\title{
Fractal Aspects of Natural Growth
}

\author{
THEODORE MODIS
}

\begin{abstract}
The work presented here puts forward a fractal aspect of natural growth. The S-shaped pattern of a logistic function is analyzed in terms of several constituent logistic functions. The approach sheds light on two familiar phenomena: the undulatory evolution of growth, which gives rise to an alternation between high- and low-growth periods, and the increasingly noticeable shrinking life cycle of products. There are some economic and political implications for the European nations. A quantitative example is given for computer sales from Digital Equipment Corporation. The approach is further generalized to suggest that any growth process can be analyzed in terms of natural-growth subprocesses. Applied to human growth this analysis yields precise definitions for the timing of transitions such as babyhood to childhood, and childhood to adolescence.
\end{abstract}

\section{Introduction}

The logistic function has well served the description of growth for such processes as species occupying ecological niches, products occupying market niches, and knowledge accumulating according to learning curves. Since its conception by Verlhust 150 years ago, this idealized S-shaped natural-growth pattern has been treated by elegance-seeking scientists as a symbol for order, equilibrium, and naturalness.

In recent years, chaos scientists have been making unremitting attacks on logistic growth and its inherent aspects of order and predeterminism. Ironically, they admit that the Verlhust equation lies at the heart of chaos, which demonstrates a "strange kind of order." Not surprisingly, the link between order and chaos has drawn attention from scientists who have approached it from both sides [1-4].

In the work reported here, a fractal aspect of natural growth is put forward. It illuminates two familiar characteristics of growth processes, the undulatory evolution that gives rise to successive high-growth low-growth periods, and the increasingly noticeable shrinking life cycle of products. The idea of analyzing a growth process in terms of subprocesses is then further developed in the tradition of a Fourier analysis so that any growth process can be decomposed in logistic "harmonics." The procedure can yield understanding and insights. It reveals, for example, precise definitions hidden behind colloquial terms referring to the growth of children.

THEODORE MODIS is a physicist and a strategy consultant at Digital Equipment Corporation International. 


\section{Growth in Successive Stages: From Chaos to Order}

The logistic curve of Equation (1) describes the process of filling a niche to capacity:

$$
f(t)=\frac{C}{\left(1+e^{-a\left(1-t_{0}\right)}\right.}
$$

where $C$ is the niche capacity, $\alpha$ is a time constant inversely proportional to the width of the life cycle of the process, and $t_{o}$ is a constant.

But a new niche may open next to or even inside the old niche. For example, the acquisition of vocabulary by an infant follows a logistic trajectory and reaches a ceiling of 2500 words at the end of age six, which represents the niche of words used by the two parents at home $[5,6]$. It is clear that subsequent education at school, or later moving to a foreign country results in successive growth patterns reflecting a stepwise acquisition of vocabulary.

It is the rule rather than the exception that growth proceeds in stages. A logistic description would be appropriate as long as the growth stage represents the filling of a niche with limited capacity. The succession of growth processes is depicted by the upper graph in Figure 1. The pattern is a schematic representation of cascading growth phases fashioned after the detailed work in a previous publication [4]. The lower graph shows the rate of growth, namely the derivatives of the logistic functions, whose envelope depicts a periodic alternation.

Depending on the timing of the two stages we can discern two distinct time periods. The steeply rising period when the growth rate is maximal, and the flat period after the old process has finished but before the new one has started when the growth rate is minimal. These two periods are fundamentally different, they require individual attention and deserve in-depth understanding.

One characteristic of the low-growth period is that as the population approaches the ceiling, fluctuations may become progressively more visible. This will not be the case with cumulative indicators (for example the height of a sunflower seedling) because of the nature of the accumulation process. But for such niche-filling processes as annual car registrations in Japan, there are fluctuations everywhere and they become much more visible as the population approaches the ceiling [7]. It has been shown that a chaoslike state may precede as well as follow the rapid-growth phase for cases of noncumulative growth [4]. These instabilities can be interpreted as a random search for the equilibrium position between the "pressure" of the growing population and the limiting capacity of the niche. The system explores upward and downward while "hunting" for the ceiling value. If the optimal level is found, a regular oscillation may persist as a telltale signal of the regulating mechanism. If such a level cannot be found, erratic fluctuations may ensue, producing a state of chaos.

The chaotic search is like mutations that during adverse environmental conditions are given a chance to explore different directions until a "gifted" one gives rise to the next phase of growth. The low-growth period is the time of profound changes when innovations and discoveries abound, and enterprises segment, decentralize, and encourage entrepreneurship. The seasonal jargon of management gurus during this period revolves around such terms as reengineering, empowerment, culture-driven, downsizing, and selforganizing entities.

In contrast, the high-growth period is the time to be conservative. You do not tamper with something that works well. During this time companies become centralized, they 


\section{Cycling Between High Growth and Low Growth}

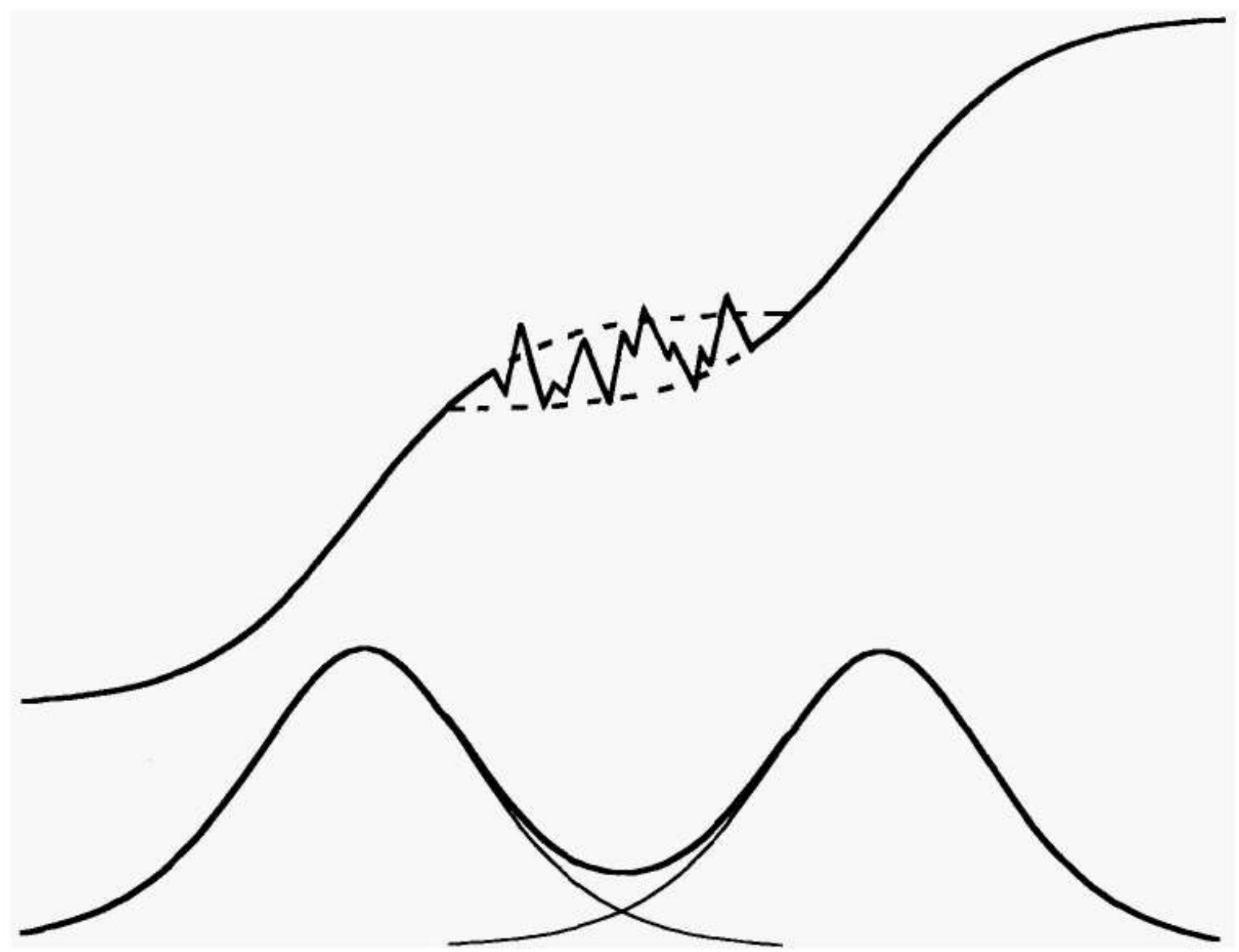

Fig. 1. Typical succession of growth processes. The graph at the top shows the amount of growth achieved. It is a schematic adaptation from detailed work that connects natural growth and chaoslike states [4]. The graph at the bottom shows the rate of growth. The overall rate of growth at the bottom (thick line) reveals a cyclical pattern. During low-growth periods chaotic oscillations become evident.

consolidate, integrate vertically or otherwise, they tune themselves into a clockwork operation and progressively develop heavy bureaucracies. The management jargon now gravitates around terms like leadership, vision-driven, control, vertical integration, acquisitions, and investments.

Cascading growth processes can be encountered in all human affairs. Chains of logistic functions with different time scales may proceed in parallel. Although the world economy goes through a long wave with successive stages of high growth and low growth, nations, companies, and individuals trace their own cycles.

It is not only economic growth that shows this alternation between order and chaos. Political growth depicts a similar evolution. For example, although the economy is actually at a low-growth phase worldwide, the political scene in Europe features two opposite camps. Western European countries have undergone a considerable political development and are now reaching a phase of maturity in that growth process. Consequently they are uniting, for example, the Economic European Community. Such actions are timely and 
portend a dominant role in world economy during the next growth phase. (This promise becomes enhanced by the dire demand for development of the European Economic Community (EEC's) next door neighbors, the central and eastern European countries.)

At the same time, central and eastern European countries find themselves at the very beginning of a politicization process. They have just acquired their political freedom and all growth processes in that domain are in their infancy, and consequently at the state of chaos that precedes a growth phase. Appropriately, these countries are decentralizing, segmenting, subdividing, searching for identity and political system, and in general, exploring all directions including extreme ones such as private police units in Moscow and murderous belligerencies in ex-Yugoslavia. Leaders currently play an important role in western Europe, and despite singular examples of populous rebellion, for example, Denmark's rejection of Maastricht at first - the name of the political game is unity. In contrast, leaders are ineffective in eastern Europe. In contrast, leaders are ineffective in eastern Europe. Exceptionally gifted individuals like Gorbachev, Shevardnadze, and Yeltsin find themselves incapable of controlling cultural forces. Politically it is a period of chaos there, and the leaders' only reasonable hope is that they will survive until the "sprouting" of the upcoming growth phase.

\section{Fractal Growth and Shrinking Product Life Cycles}

Successive growth stages depicted by cascading logistic curves may outline an overall growth process that is itself amenable to a logistic description. Two such examples from published work are the discovery of stable chemical elements, which spanned three centuries and can be broken down into four rather distinct regularly spaced growth phases $[8,9],{ }^{\prime}$ and the diffusion of Italian railways which came in three waves [10].

The idea that a growth process can, on closer examination, reveal similar but smaller cascading growth processes, suggests a fractal nature for the logistic curve. The implication is that further "zooming-in" may reveal an even finer structure of logistic cascades. In an effort to show this pictorially, the graph of Figure 2 was constructed. The process in question deals with ideal logistic growth such as a cumulative-growth process, in which the question of superimposed fluctuations becomes of secondary importance.

The construction of this graph imposed several conditions. First, the overall logistic pattern had to be given a certain "thickness" within which the constituent logistics would be contained. Second, in order to eliminate redundant solutions, a rule had to be imposed characterizing the constituent functions as belonging to one class. Finally there was the obvious constraint that the life cycle of the envelope process must be greater than the life cycles of the constituents.

The rule chosen to define a class of logistics was that they all have the same slope at their midpoint, in other words, that the maximum rate of growth is the same for all subprocesses. Such a rule has a defensible interpretation when it comes to product sales, because it reflects the stability of consumer spending. People's average income (Gross National Product) does not change appreciably with time, and therefore the buying power of individuals of a certain income class also remains stable. As products come and go substituting each other, the maximum rate of product sales does not change on the average, and the larger the product niche the longer its life cycle. As a consequence, life cycles

\footnotetext{
${ }^{1}$ In 1980, Cesare Marchetti hinted that chemical-element discovery may be linked to Kondratieff's cycle, see reference [5] above. I have shown this to be indeed the case in my book Predictions, Simon \& Schuster, New York, 1992.
} 


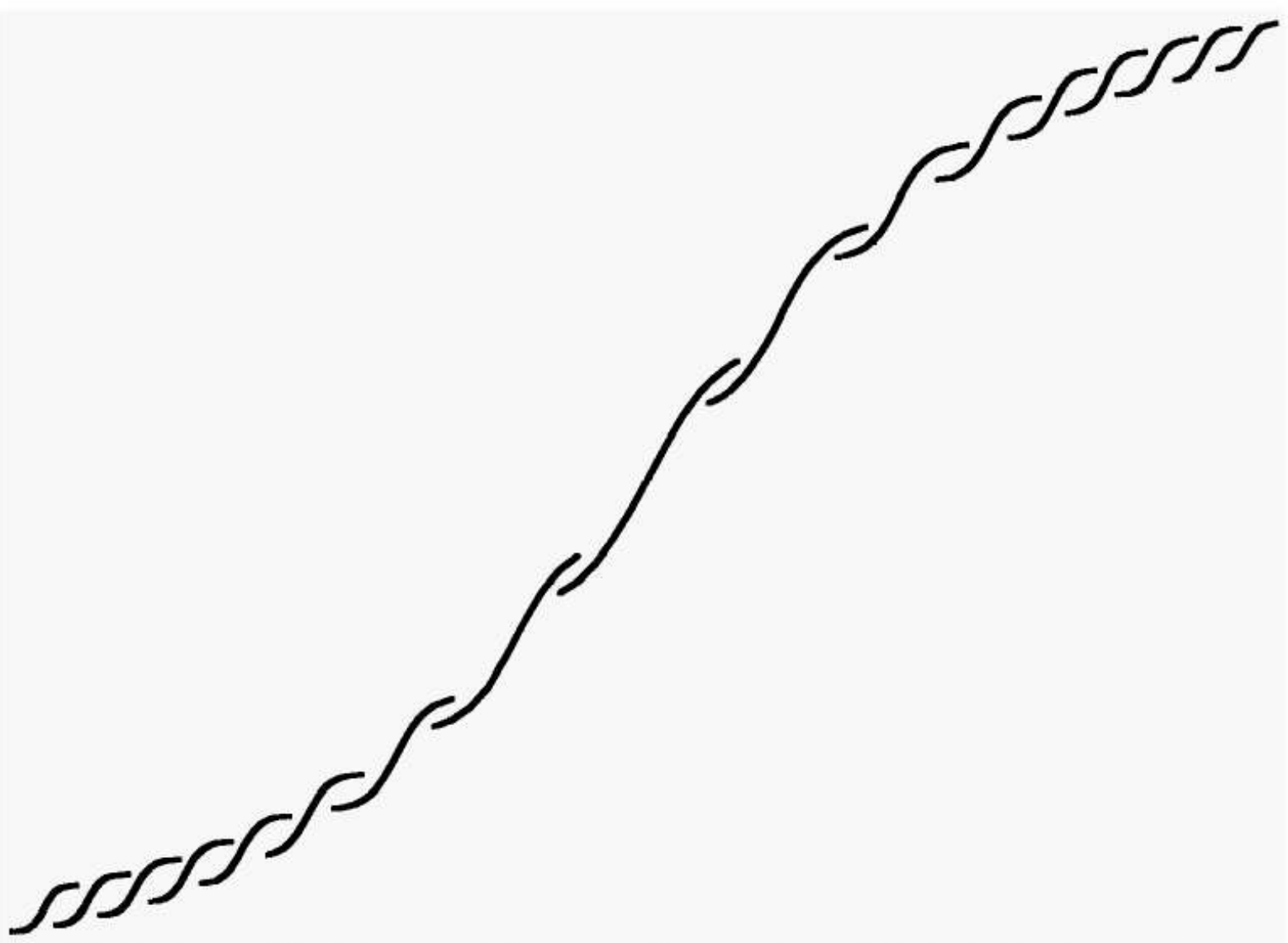

Fig. 2. An overall logistic pattern is decomposed into constituent logistics. The horizontal axis represents time. See text for graph details.

become longer during the high-growth period and shorter during the low-growth period as depicted in the sketch of Figure 3.

The phenomenon of shrinking life cycles, an important concern of today's manufacturers, can be quantitatively linked to the saturation of the enveloping process. Table 1 relates the shortening of product life cycles to the level of saturation reached. The table entries reflect the typical situation depicted in Figure 2. The parameters of the overall logistic were $C=10$ and $\alpha=0.2$. The thickness assigned was \pm 0.2 . For all constituent logistics $C \cdot \alpha=3$. The values of Table 1 were calculated numerically. They proved rather stable against variations of most of the chosen parameters. The shrinking of life cycles became more dramatic when the duration of the envelope cycle was increased, but this effect was largely compensated for when the assigned thickness was decreased in proportion.

For a particular family of products, see example of Digital's MicroVAX family below, shrinking life cycles reflect exhaustion of the technology in question. On a much larger scale, the simultaneous shrinking of life cycles in many industries reflects a global economic saturation. Monitoring the drift of the width of life cycles over time can tell us how close we are to full saturation or, alternatively, it may tell us how far we are from a rapid-growth phase.

\section{AN EXAMPLE FROM DIGITAL}

In 1984 Digital Equipment Corporation introduced a line of microcomputers called MicroVAX. They were sold largely in a microniche: the range of prices for computer configurations between $\$ 20,000$ and $\$ 50,000$. At older times, this price range was occupied 


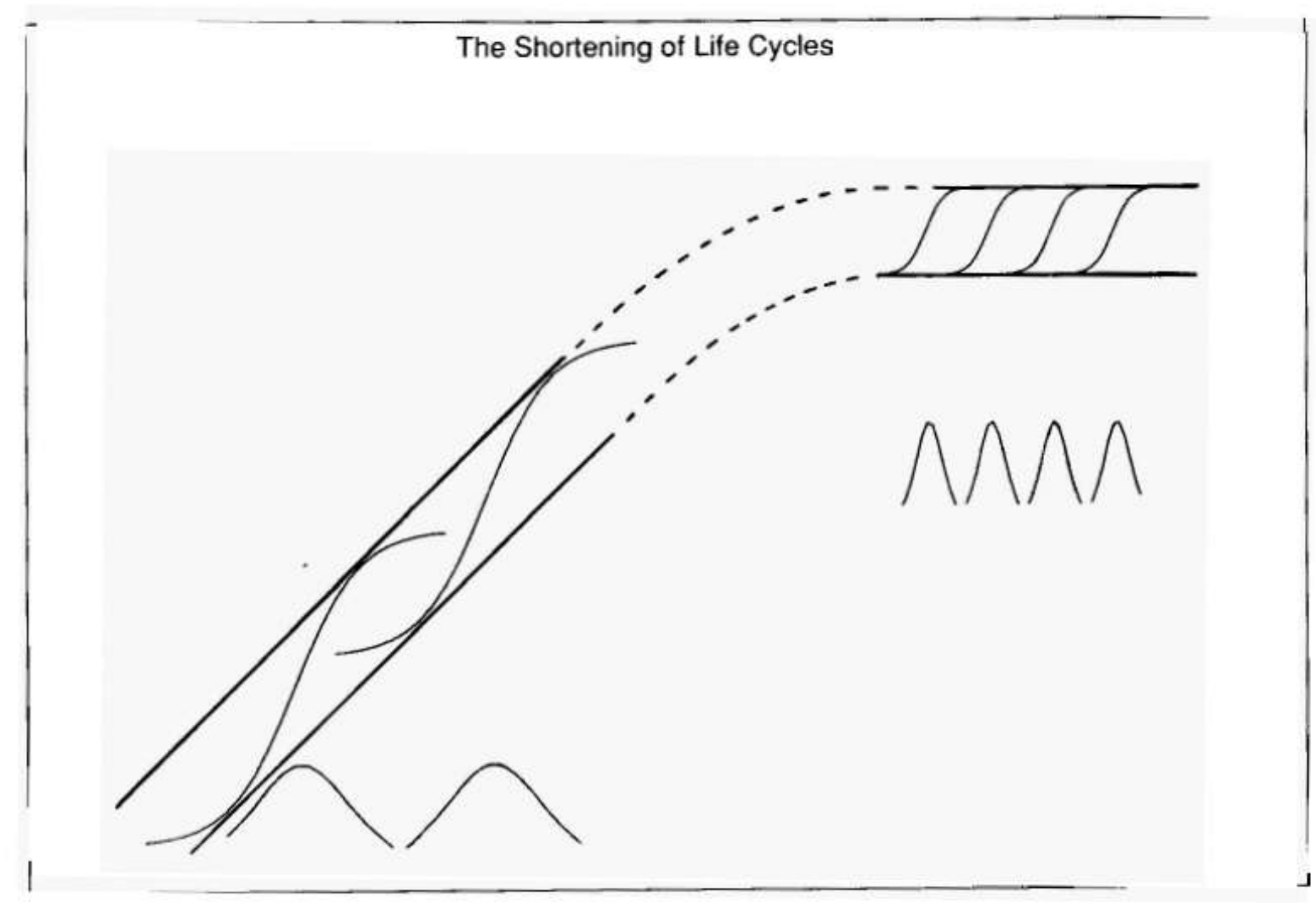

Fig. 3. An artist's view of why the end of growth implies shorter life cycles.

TABLE 1

The Relation between the Shortening of Life Cycles and Saturation

\begin{tabular}{cc}
$\begin{array}{c}\text { The Relation between the Shortening of Life Cycles and Saturation } \\
\text { (relative to longest) }\end{array}$ & $\begin{array}{c}\text { Level of saturation } \\
\text { (percent of ceiling) }\end{array}$ \\
\hline 0.17 & 3.1 \\
0.19 & 4.0 \\
0.20 & 5.2 \\
0.22 & 6.9 \\
0.24 & 9.1 \\
0.30 & 12.8 \\
0.41 & 20.0 \\
0.70 & 31.4 \\
1.00 & 50.0 \\
0.70 & 68.6 \\
0.41 & 80.0 \\
0.30 & 87.2 \\
0.24 & 90.9 \\
0.22 & 93.1 \\
0.20 & 94.8 \\
0.19 & 96.0 \\
0.17 & 96.9 \\
\hline
\end{tabular}

6 
TABLE 2

Results from Fits on Products

\begin{tabular}{lrrrrrr}
\hline \multicolumn{1}{c}{ Model(s) } & \multicolumn{1}{c}{ C } & \multicolumn{1}{c}{$\alpha$} & \multicolumn{1}{c}{$\begin{array}{c}\text { Average } \% \\
\text { deviation }\end{array}$} & $\begin{array}{c}\text { Correlation } \\
\text { coefficient }\end{array}$ & $\begin{array}{c}\text { Life } \\
\text { cycle }\end{array}$ \\
\hline MicroVAX I & 813.07 & 0.9225 & 3.795 & 5.825 & 0.99773 & 1.084 \\
MicroVAX II & $14,536.00$ & 0.3302 & 12.871 & 5.188 & 0.99857 & 3.028 \\
M2000 & 4786.80 & 0.6013 & 17.935 & 5.584 & 0.99912 & 1.663 \\
M3500/3800 & 687.17 & 0.6206 & 22.676 & 16.869 & 0.98704 & 0.806 \\
M3300/3400 & 3006.00 & 0.5122 & 24.602 & 6.841 & 0.99806 & 0.976 \\
M3100/10/20 & $11,617.00$ & 0.4707 & 29.007 & 4.492 & 0.99900 & 0.708 \\
Accumulation of market share & & & & & & \\
$\quad$ (arbitrary units) & 16.387 & 0.12301 & 13.842 & 5.584 & 0.99919 & - \\
\hline
\end{tabular}

a The units of time are quarters and they start with Q3FY84.

${ }^{b}$ Calculated as $1 / \alpha$ divided by the number of models involved.

c The best fit was obtained when an early missing-data parameter was allowed to float to 3.162 indicating that $19.3 \%$ of the early process was missing. This probably reflects the widely accepted notion that MicroVAX had been overdue and that a certain amount of pent-up demand had been built.

by another line of microcomputer called PDP. When MicroVAXes appeared, they progressively displaced the old machines. Presently, this price range is being taken over by workstations and servers. The MicroVAX family is phasing out like a single product even though a dozen different models have been sold and each followed its own logisticgrowth curve.

Logistic fits have been carried out for the 10 models that have practically completed their life cycle. The fit parameters are shown in Table 2 . Figure 4 shows the evolution of the life cycle duration taken as $1 / \alpha$ for single products, and timed by the parameter $t_{0}$.

MicroVAX I was the family's first entrant, it had a short life cycle, and it was generally considered an unsuccessful product. Unfairly so, it should rather be seen as an "exploratory" attempt that paved the way for the products that followed. MicroVAX II had the longest life cycle. The life-cycle duration already started decreasing at the time of M2000. The peak of a smoothed distribution would fall somewhere around the end of fiscal year 1987.

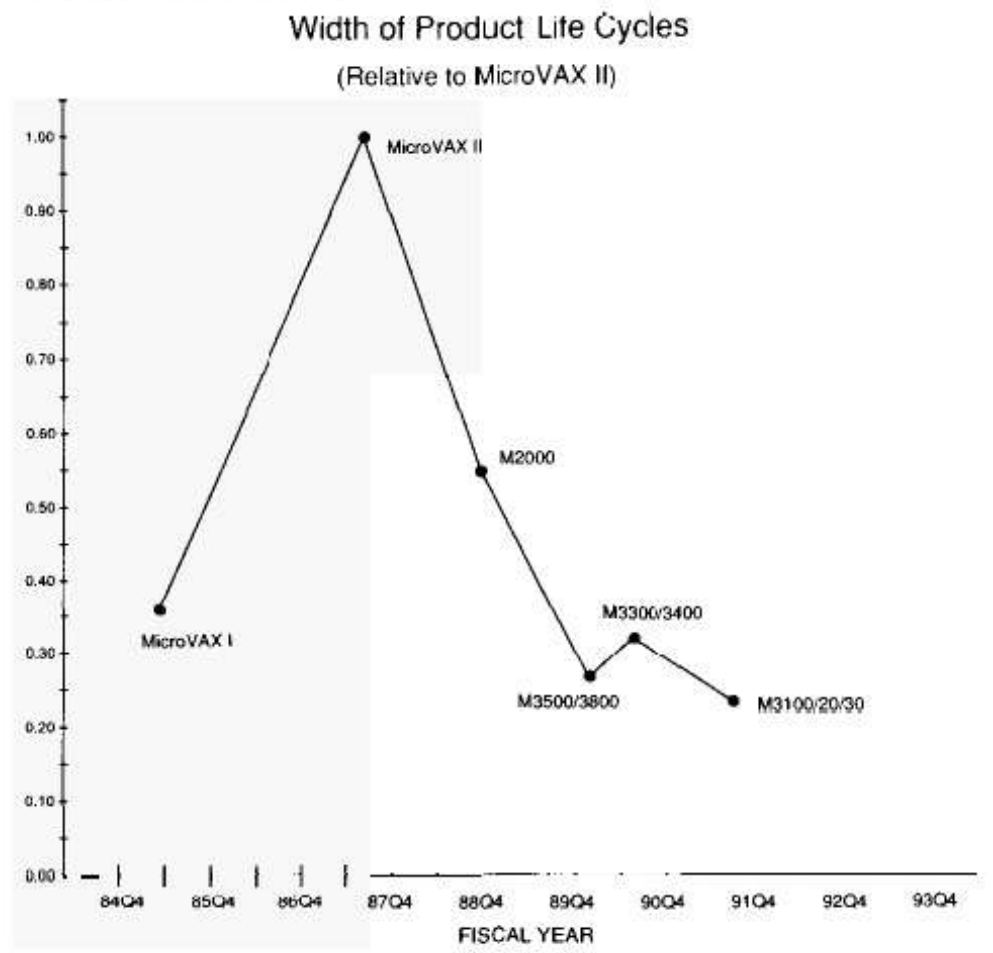

Fig. 4. The rise and fall of product life cycles in the MicroVAX family of Digital Equipment computers. The data come from Table 2 . 


\section{The MicroVAX Growth Process}

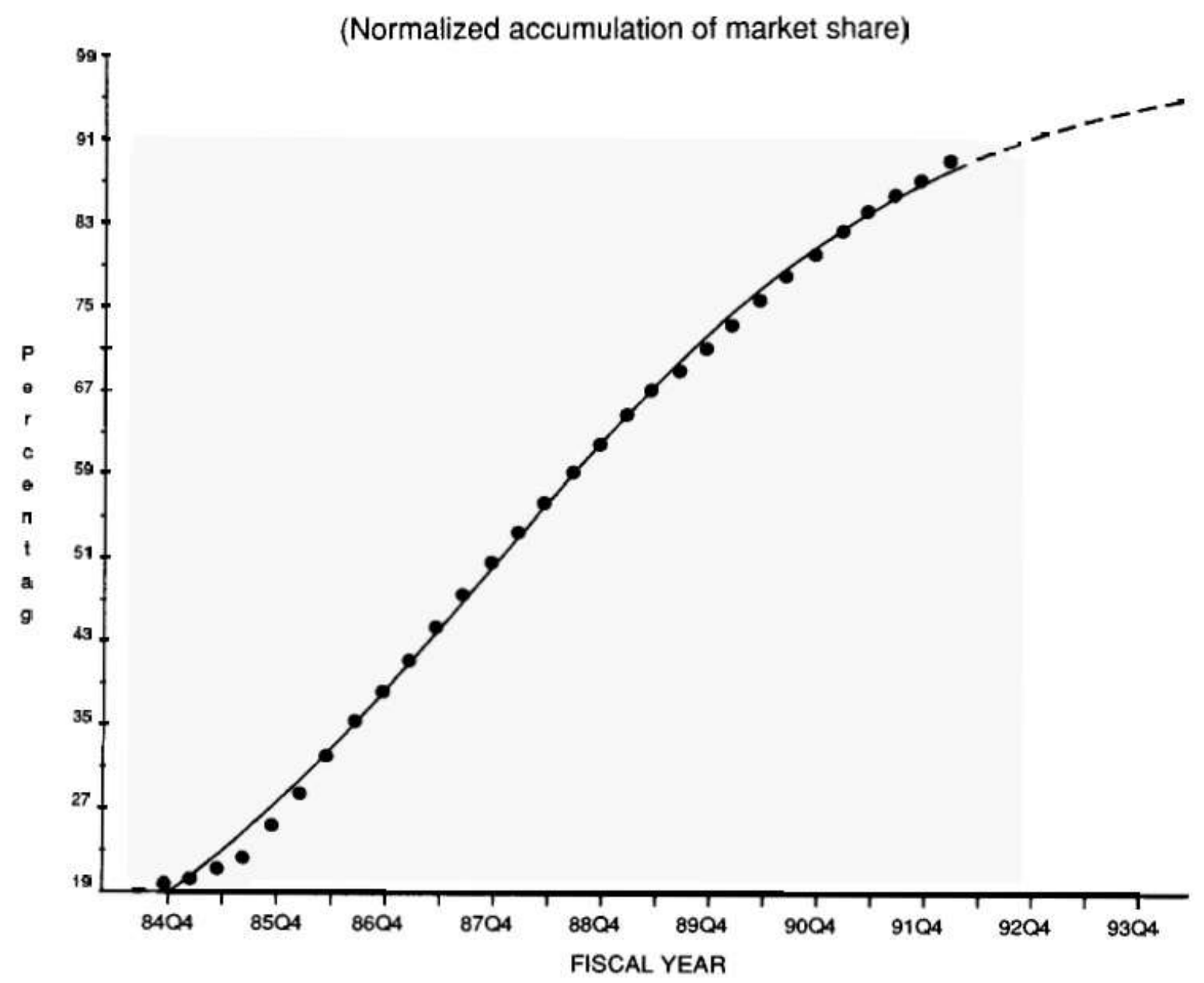

Fig. 5. The MicroVAX story as reflected by the technology's ability to fill its own market niche. The data points represent the accumulation of market share. The line is a logistic fit up to the second quarter of fiscal year 1992. The process is normalized to $100 \%$ at the ceiling of the fitted line. $A$ jump from 0 to $19 \%$ at the beginning corroborates the notion of a sudden release of pent-up demand due to a delayed appearance.

Despite a limited resolution (only a small number of models) the evolution of MicroVAX corroborates the fractal aspect of logistic growth. The variation of the life cycles in conjunction with the results of Table I provide us with estimates for the overall saturation of the family. For example, M2000, M3300/3400, and M3100/10/20 have life cycle durations relative to MicroVAX II of $0.55,0.32$, and 0.23 respectively, which places them at respective saturation levels of $74 \%, 87 \%$, and $92 \%$. We can try to obtain an independent estimate for these levels by analyzing the growth of MicroVAX as a single process.

Because of the general trend toward smaller computers, the importance of MicroVAX over time is best represented by its market share in the microniche considered. The share rose and declined over the lifetime of this product line. The process of accumulating market share was fitted to a logistic curve in Figure 5. The fit parameters are given in Table 2.

In order to focus on the rate of penetration of the MicroVAX technology, the vertical scale is normalized to $100 \%$ when the process of accumulating market share reaches a ceiling. We can thus read saturation levels directly as a function of time. The starting point 
is a significant $19 \%$ reflecting the release of a certain pent-up demand (see explanatory note in Table 2). At the times corresponding to the three examples mentioned above we find $63 \%, 80 \%$, and $87 \%$, respectively. These results are in fair agreement with the estimates obtained in the previous paragraph considering the various sources of uncertainty. Uncertainties come from having too few products, lumping them together at times, and a skewed distribution (MicroVAX II is not exactly at the center).

Being able to estimate the level of overall saturation from observing life cycle trends is a powerful approach. It implies that a nonspecialist, such as a laborer loading boxes into trucks off the manufacturing dock, may notice that the names on the boxes change three times as frequently as they used to and deduce that the technology behind these products is more than $80 \%$ exhausted. This image may be naive, but the approach offers valuable insights for those situations in which the tracking of the overall envelope is rather imponderable. For example, "zooming" backwards, we might expect the different families of VAXes to behave as the "products" that make up the overall growth curve of the VAX architecture. Carrying this further, we may want to see the different architectures, such as PDP, VAX, and ALPHA to behave as product-like components of the grand envelope describing the company's global evolution. In each level, an observation on the evolution of the durability of "products" provides information on the state of exhaustion of the "family."

\section{Decomposition of Any Growth Pattern into Logistic Components}

The decomposition of an overall growth process into fine-grained logistic sections can be generalized in the tradition of a Fourier analysis. Instead of sines and cosines one can in principle decompose a function into logistic functions. For a given process we may find that one logistic component plays a major role, even if the overall pattern shows significant deviations from an S-shaped pattern. In an analogous Fourier analysis we would say that this is the fundamental harmonic and that higher harmonics are expected to play less important roles.

Describing a function as a sum of terms belonging to a class of functions is an old mathematical pastime and one may question here the usefulness of proposing yet another such academic exercise. We see below an example in which decomposition into logistics reveals unexpected rigor behind the definitions of colloquial expressions.

The growth in the size of a human male from embryo to adulthood is shown in Figure $6[11,12]$. Superimposed on the data are logistic curves covering sections of the overall process.

The analyzing approach was to describe the complete data set with as few logistic functions as possible. The first logistic covers the period of gestation and extends to sometime beyond the age of one. The second logistic covers from 2 to 12 years of age. The excess between ages 13 and 19 is amenable to a third logistic fit. The results from the fits are shown in Table 3. The fitting procedure involved the minimization of a Chi squared function. ${ }^{2}$ The goodness of the fits deteriorates rapidly with changes in the definition of the data sets.

The "fundamental harmonic" is childhood. Only half of a logistic function is used for its description but it contributes the largest-size chunk to one's height and covers more than $90 \%$ of one's total-growth period. Second in importance is the fetus/baby growth process with a comparable contribution to the final height but a much shorter

\footnotetext{
${ }^{2}$ Use was made of a function minimization program called MINUIT, developed at the Euroepan Center for Nuclear Research (CERN) in Geneva Switzerland.
} 


\section{The Stages of Human Growth}

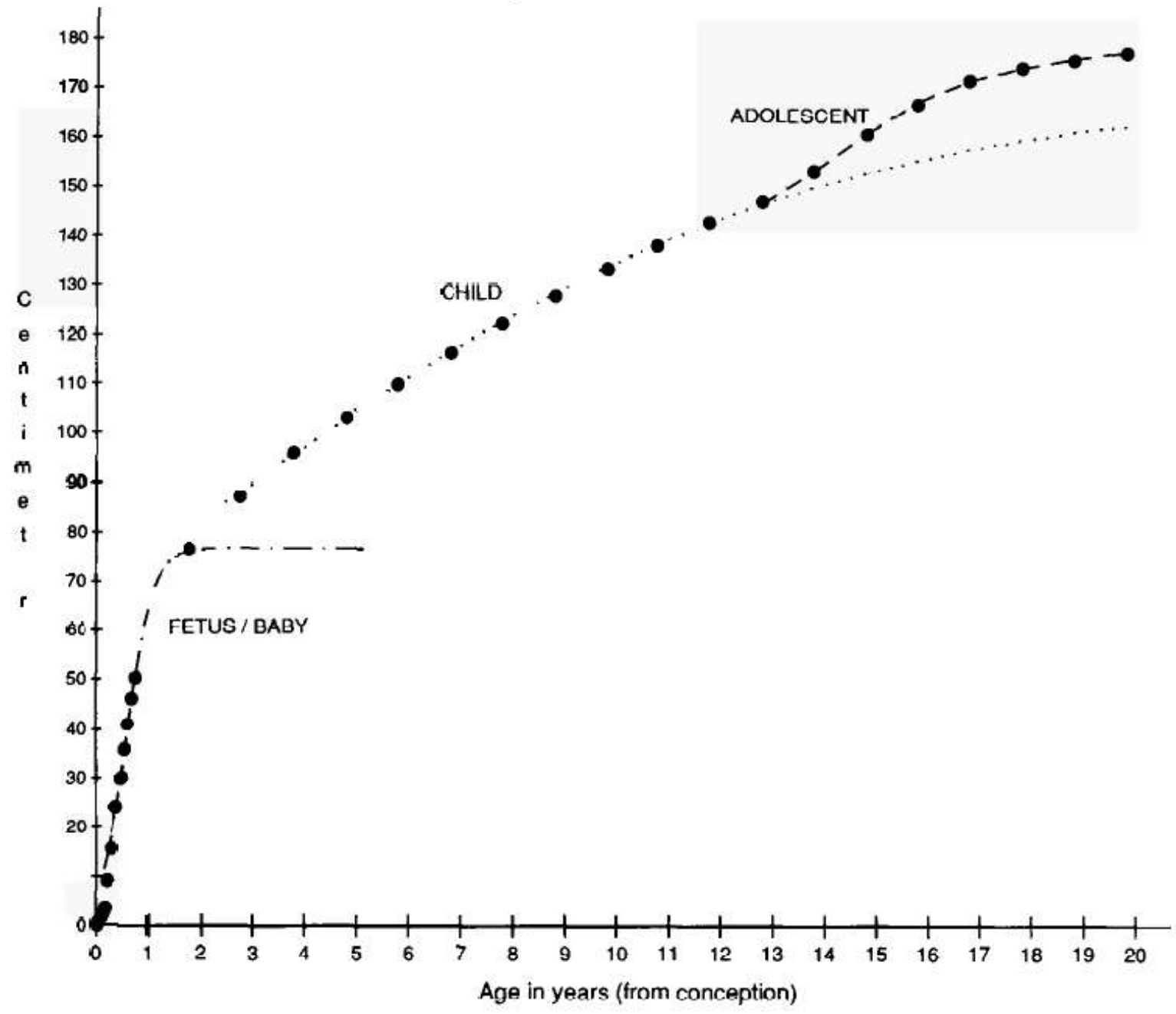

Fig. 6. Data and fits for the phase of growth in size of a human male. The results are listed in Table 3.

time constant. Adolescence is a higher-order effect (less pronounced for girls), that begins at age 13 and contributes less than $10 \%$ of the total height. A more in-depth study may discern a finer logistic-growth processes around the egg and the embryo states. Finally, there must be a relatively minor downward pointing logistic function describing the shrinking of one's height with old age.

TABLE 3

Results from the Fits

\begin{tabular}{lrccccc}
\hline Growth phase & \multicolumn{1}{c}{$\mathrm{C}^{b}$} & $\alpha$ & $\mathrm{t}_{\mathrm{n}}{ }^{\mathrm{b}}$ & $\begin{array}{c}\text { Average } \% \\
\text { deviation }\end{array}$ & $\begin{array}{c}\text { Correlation } \\
\text { coefficient }\end{array}$ & $\begin{array}{c}\text { Range of } \\
\text { age fitted }\end{array}$ \\
\hline Fetus/baby & 76.809 & 4.0194 & 0.5879 & 7.80 & 0.99441 & $0.23-1.77$ \\
Child & 169.475 & 0.1770 & 2.3164 & 0.40 & 0.99963 & $2.77-12.77$ \\
Adolescent & 15.078 & 1.3181 & 14.709 & 2.54 & 0.99854 & $13.77-19.77$ \\
\hline
\end{tabular}

The time units are years and start at conception.

s The units of height are centimeters.

c The best fit was obtained when an early missing-data parameter was set to 76.91 representing the Fetus/baby growth. Consequently, the contribution of childhood to the total height is close to $169.475-76.91=92.565 \mathrm{~cm}$. 
An emerging conclusion is that everyday terms such as fetus, baby, child, and adolescent have precise definitions reflecting growth processes that are distinct. The fact that fetus and baby belong to the same growth curve must be related to the fact that the distinction between these two states is largely a "geographical" one, meaning inside or outside the womb. Afterall, the transition between them takes place abruptly, the ratio of gestation to babyhood from case to case could vary up to factors of 3 , and the exact time of transition is most often arbitrary (induced labor).

\section{References}

1. Peitgen, H. O., and Richter, P. H., The Beauty of Fractals, Springer-Verlag, Berlin, 1986.

2. Gleick, J., Chaos, Viking, New York, 1987.

3. Briggs, J., and Peat, F. D., Turbulent Mirror, Harper \& Row, 1989.

4. Modis, T., and Debecker, A., Chaoslike States Can Be Expected Before and After Logistic Growth, Technological Forecasting \& Social Change 41, 111-120 (1992).

5. Whiston, T. G., Life Is Logarithmic, in Rose, J., ed., Advances in Cybernetics and Systems (London: Gordon and Breach, 1974).

6. Marchetti, C., Society as a Learning System: Discovery, Invention and Innovation and Innovation Cycles Revisited, Technological Forecasting \& Social Change, 18, 267-282 (1980).

7. Marchetti, C., The Automobile in a System Context: The Past 80 Years and the Next 20 Years, Technological Forecasting and Social Change, 23, 3-23 (1983).

8. de Solla Price, D. J., Little Science, Big Science, Columbia University Press, New York, 1963.

9. Montroll, E. W., and Badger, W. W., Introduction to Quantitative Aspects of Social Phenomena, Gordon and Breach Science, New York.

10. Marchetti, C., Fifty-Year Pulsation in Human Affairs, Analysis of Some Physical Indicators, Futures, 17 (3), 376-388 (1986).

11. Laffont, A., and Durieux, F., Encyclopédie Médico-Chirurgicale, Éditions Techniques, Paris, 1985.

12. Kaufmann, Lang, and Rieben, Croissance de la taille et du poid de 4 à 19.5 ans-Garçons et filles suisses domiciliés dans le canton de Genève en 1972, Editions Médicine et Hygiène, Geneva, 1976. 